\title{
Acute generalized exanthematous pustulosis
}

INSERM

\section{Source}

INSERM. (1999). Orphanet: an online rare disease and orphan drug data base. Acute generalized exanthematous pustulosis. ORPHA:293173

A rare toxic dermatosis disease characterized by the rapid development of numerous, nonfollicular, sterile, pinhead-sized pustules on an edematous and erythematous base, predominantly occurring on the trunk, intertrig inous and flexural areas, with rare, mostly oral, mucosal involvement. Acute onset of fever $\left(>38^{\circ} \mathrm{C}\right)$, peripheral blood leukocytosis, and mild eosinophilia are accompanying features. Systemic involvement, with hepatic, renal or pulmonary dysfunction, occasionally occurs. Histologically reveals characteristic spongiform, subcorneal and/or intraepidermal, pustules, as well as marked edema of the papillary dermis, a perivascularly accentuated, neutrophil-rich inflammatory infiltrate, and intrapustular or intradermal eosinophils. 